\title{
Demographics and Asset Markets: A Survey of the Literature
}

\author{
Wasanthi Thenuwara*, Mahinda Siriwardana, Nam Hoang \\ UNE Business School, University of New England, Armidale NSW, Australia \\ Email: *wthenuwa@myune.edu.au
}

How to cite this paper: Thenuwara, W., Siriwardana, M. and Hoang, N. (2017) Demographics and Asset Markets: A Survey of the Literature. Theoretical Economics Letters, 7, 782-794.

https://doi.org/10.4236/tel.2017.74057

Received: April 25, 2017

Accepted: June 11, 2017

Published: June 14, 2017

Copyright (c) 2017 by authors and Scientific Research Publishing Inc. This work is licensed under the Creative Commons Attribution International License (CC BY 4.0).

http://creativecommons.org/licenses/by/4.0/ (c) (i) Open Access

\begin{abstract}
This paper surveys the theoretical and empirical literature examining the effects of population age structure on financial asset prices, including critical reviews of the methodologies used and an evaluation of contradictory results. The survey focuses on the effects of the Baby Boom generation on asset prices, and in particular, the question of the asset meltdown hypothesis (AMH). The existing literature reveals that an asset meltdown may never eventuate nevertheless it remains plausible that ageing of the Baby Boomers will have a significant negative impact on asset prices. The previous studies were based on where the proportion of the old age population is relatively low. With the first Baby Boomers reaching 65 years of age in 2011 this proportion is projected to increase substantially and hence the effect is reinforced. Thus new research is needed to address the unresolved issues given that population ageing has serious policy issues in the developed economies.
\end{abstract}

\section{Keywords}

Ageing, Asset Prices, Asset Meltdown Hypothesis, Baby Boom, Demography, Demographic Structure

\section{Introduction}

Since the late 1980s, academic researchers, analysts and investors have been studying the pressure exerted by demographic transitions, particularly the rapid ageing of the population, on various sectors in the economy. Among these effects, the impact on economic growth, consumption, savings, capital flows, government expenditure and asset prices are of particular significance. The life cycle theory of consumption and savings analyze the saving and consumption behaviour of individuals over the different stages of their lives Modigliani and Brumberg [1], Ando and Modigliani [2]. The theory posits that the saving behaviour of the households (save during the working age and dis-save during the retire- 
ment) exhibits a demographic transition not a steady state growth.

The Baby Boom generation, those born between 1946 and 1964, is a significant demographic group in developed countries. Conversely, the Baby Bust generation (born 1967-1979) is a much smaller group. The significant differences in the numbers in the boom and bust groups along with increasing life expectancy have brought OECD countries to the onset of a rapid demographic transition. The average and median ages of populations across the OECD countries have been increasing, while the average life expectancy rose from 69 years in 1970 to 80.5 years in 2013 [3]. The first boomers reached retirement age in 2011 and by 2030 all of the living members will have reached retirement age. The United Nations population projections indicate that the average old age dependency ratio (65+ years/15 - 64 years) will increase from $22 \%$ in 2010 to $35 \%$ in 2030 .

When Baby Boomers initially entered the labour market there were fears about increases in unemployment levels and the reduced wage rates. However, the debate turned to the impact on asset markets as the Baby Boom cohort aged. For example, a substantial number of researchers link the rise in the U.S. stock prices in the 1990s to the increase in savings as the working-age Baby Boomers saved for their retirement. It is argued that this led to an increase in the demand for financial assets and a dramatic rise in financial asset prices. With the present need to provide for an increasing proportion of the population who are retired, a concern has arisen about a downward pressure on asset prices. This intuition has given rise to the asset meltdown hypothesis (AMH). Siegel [4] describes this scenario as:

The words "Sell? Sell to whom?" might haunt the Baby Boomers in the next century. Who are the buyers of the trillions of dollars of boomer assets? The [Baby Boomer generation] ... threatens to drown in financial assets. The consequences could be disastrous for the boomers' retirement but also for the economic health of the entire population.

Many empirical studies use the life cycle hypothesis to investigate the effect of a changing population age structure on asset markets. The population age structure primarily affects savings though rational economic agents investing in housing and financial assets. Furthermore, overlapping generations models (OLG) are the natural framework to model an individual's distinct financial needs at different periods of life, such as borrowing when young, saving for the retirement in the middle-aged life and dis-savings at the retirement [5]. It is, therefore, likely that the changing demographic structure may have an impact on asset markets. In this paper we critically review the existing literature on the impact of population ageing on financial asset prices/returns and assess the explanations, limitations and shortcomings in the empirical methodologies used.

The remainder of the paper is organised as follows. Section 2 highlights the motivation and the significance of the survey. Section 3 reviews the theoretical literature. Following a review of the empirical literature in Section 4, the Section 5 presents a summary of literature and a discussion. The last section provides conclusions drawn from the survey. 


\section{Motivation and Significance of the Survey}

The existing literature establishes the relationships between demographic changes and asset prices/returns for a period when the proportion of old aged and retired people was comparatively low. With the first Baby Boomers having reached 65 years of age in 2011 this proportion is projected to increase to an unprecedented level. Policy changes are being made to offset the effects of this trend, with 28 out of 34 OECD countries having increased or planning to increase the retirement age [6]. With updated data results of previous studies may change substantially in future research. Moreover, in contrast to the experiences of population ageing in developed countries, developing countries are still experiencing rapid population growth with low average ages. These divergent demographic trends along with the increasing globalization of financial markets may exert changes in savings patterns and on asset markets. This survey of literature is appropriate and significant at this time to summarise what we already know about the dynamics of population ageing and the impact on asset prices/returns and to point a direction for future research.

\section{A Review of the Theoretical Prediction}

Theoretical studies suggesting a plausible link between asset prices/returns and the demographics adopt different modelling structures. The results from such modelling can be either from simulations or analytical. In the framework of an OLG model and based on simulation results, Yoo [7] finds that $1 \%$ increase in the proportion of population over the age 45 years leads to a reduction in asset returns of $2 \%$ in the United States. Yoo [8] further develops the model to incorporate the age distributions generated by the stylised Baby Boom in the United States. The results show the clear impact of Baby Boomers on asset prices, raising asset prices by $33 \%$ above the steady state. However, Yoo's simulation results focus on a single steady state and ignore the adjustment process from one steady state to another.

Brooks [9] augments a real business cycle model with an OLG model that assumes an individual has four periods; childhood, young working age, old working age and retirement. The simulation results indicate that old agents are risk aversion. Young workers invest in risky capital while old workers invest in safe bonds. Thus the results indicate that when the Baby Boom generation is young and working (the 1980s) risk-free returns rise and when they reach retirement the same falls. The retirement of Baby Boomers will raise the capital-labour ratio by $15 \%$ above the steady state value in 2020 . The returns on stocks and bonds will be $0.47 \%$ and $0.55 \%$ below the steady state value in 2020 respectively. Overall, Brooks [9] concludes that although returns on Baby Boomers' savings at their time of retirement is $1 \%$ lower compared to the current rates, they will not be worse off than their parents or children.

Rational agents would anticipate the impact of a changing ageing structure on asset markets. Geanakoplos et al. [10] apply this concept and augment the OLG model and show that irrespective of whether agents are myopic or broadminded 
about the future demographics changes, a large middle-aged cohort will push up stock prices. They further show that agents' prior knowledge of the changing ageing structure reinforces the effect. This contradicts Poterba's [11] argument that incorporating rational expectations into the model negates the effects of demographics on asset prices.

The predictions of life cycle theory were supported by Abel's [12] rational expectations general equilibrium model with a bequest motive. The analytical results indicate that the Baby Boom generation drives up stock prices and predict a decline in stock prices when Baby Boomers retire in the United States. These results are not attenuated with the introduction of bequest motives to the model. However, Abel's [12] conclusions contradict Poterba's [12] empirical results that we discuss in section 3 of the paper. This is despite both (Poterba and Abel) having consistent observations about the asset holdings of the retired people. Both observe that individuals hold on to a proportion of assets that they have accumulated during their working life in retirement. This held portion is considerably higher than that predicted by a simple life-cycle model.

Abel [13] provides further analytical results using an OLG closed economy model and shows that national income and investments are high when the working age group is a large proportion of the population. Therefore, the effect of the Baby Boom is to raise the price of capital leading to an increase in the price of stocks. However, the increase in price of capital is not persistent and when the working age group becomes small as a result of the retiring Baby Boomers, the price of capital falls.

Goyal [14] uses a different theoretical approach that considers the impact of a changing demographic structure on both inflows and outflows from the asset markets and asset returns. He first analyses the intertemporal consumption-investment problem of a single agent and then aggregates the solution in an OLG framework. The results indicate a positive impact on asset market inflows from an increasing share of middle aged people. Also, the increase in the share of the old age population increases outflows from the asset market. With regard to asset returns, the increasing share of the middle aged drives up asset returns while the increase in the old aged cohort pushes down the asset returns.

The results from theoretical models are either analytical or from simulations. In both cases, results are based on intertemporal general equilibrium or OLG models. These theoretical models suggest that the working age population has a strong demand for assets and thereby raise asset prices. At the time of retirement individuals liquidate assets to finance their retirement and thereby exert a negative pressure on asset prices. This intuition prompted to the asset meltdown debate.

\section{A Review of the Empirical Literature}

The motivation for the empirical research on demographics and asset prices is the 1989 Mankiw and Weil paper on the effect of Baby Boomers on housing prices in the United States. They predicted a market "meltdown" when Baby 
Boomers began to retire. However, Mankiw and Weil's [15] startling result of real house prices falling by $47 \%$ in the United States within 20 years from the 1990s provoked considerable criticism and questioning of the validity of their forecast. With respect to the impact on financial assets, in a seminal work, Bakshi and Chen [16] analyse the extent that variations in population age structure have an impact on stock price movements using U.S. data from 1900 to 1990. Bakshi and Chen [16] formalise a life cycle investment hypothesis and a life cycle risk aversion hypothesis in an asset-pricing model. The life cycle investment hypothesis states the households' preferences regarding the types of assets they hold over the term of their life. Young households prefer to invest in housing, but as they get older they are likely to shift their preferences towards financial assets.

However, the authors do not conduct a formal empirical work to test the life cycle investment hypothesis. Instead, in support of their conclusion they use two approaches. The first is to cite existing empirical evidence supporting the hypothesis and the second is a graphical approach. Bakshi and Chen [16] conclude that the empirical evidence of Mankiw and Weil (1989) and of Bossons [17] is consistent with the life cycle hypothesis even though in both cases the analysis was cross sectional. In the graphical analysis of time series data, Bakshi and Chen [16] divide the sample into four sub-periods: 1900-1945, 1946-1966, 19671980 and 1981-1990. These sub-periods exhibit certain unique demographic features of the U.S. population, which they link to the changes in investments. Based on these two approaches Bakshi and Chen [16] demonstrate that the post1945 period is supportive of the life cycle investment hypothesis and conclude that an ageing population drives an increase in stock market prices and declining housing prices.

Bakshi and Chen [16] use a multi-period model with a representative agent to analyse the life cycle risk aversion hypothesis. The authors apply generalised methods of moments (GMM) to test the Euler Equation. The only variable that Bakshi and Chen [16] use to explain demographic changes in their regression analysis is the average age which was subsequently criticised by Yoo [7] and Paterba [18]. In contrast, many of the other studies employ proportion of the population at different ages as demographic variables which might better capture the lifetime asset accumulation profiles.

As with the Mankiw and Weil's [15] predictions of the asset price meltdown, the validity of the Bakshi and Chen [16] conclusions have been both supported and criticized. Poterba [18] criticizes the substantive importance of demographic factors in Euler equation, namely the fact that the age structure improves the fit of an Euler equation could simply reflect other failures of the Euler equation, rather than the substantive importance of demographic factors [18].

While highlighting the difficulty of applying the ideas of Bakshi and Chen [16] in an international context, Erb et al. [19] reveal a weak relation between world average demographic measures and expected returns. On the other hand, the authors find a significant correlation between all demographic variables and risk 
indicators, particularly country specific equity market risk. It should be noted that the Erb et al. [19] study is a cross sectional time series (CSTS) analyses based on 45 developed and emerging economies, where the use of average age in the regression casts doubt on the results particularly in the case of emerging economies ${ }^{1}$. Poterba [20] states "it is not clear whether such demographic changes should be viewed as the driving force behind asset market movements, or whether they in turn reflect other factors at work in developing nations".

Contrary to the strong relationships between demographic structure and asset returns found in earlier studies, Poterba [18] fails to find a robust relationship between demographic structure and the stock returns in the Unites States. However, Poterba [18] finds strong relationships between both the Treasury bill rates and long term government bond returns and demographic variables. In addition, Poterba finds a statistically significant negative coefficient for the proportion of population between ages 40 - 64 years in the regression with Treasury bill returns.

Poterba [11] re-examines the relationship between demographic structure and financial asset returns for the United States, and compares the results with Canada and the United Kingdom. Further, Poterba [11] constructs a price-dividend ratio on the S \& P 500 to incorporate the long-run movements in stock prices which would better capture the life cycle consumption decisions as theory suggests. In contrast to previous results, the estimation exhibits a strong association between demographic variables and the price-dividend ratio. However, the author establishes that these results suffer from the "spurious regression" problem.

The studies mentioned so far only consider demographic variables as the explanatory variables for asset prices. This ignores the impact of economic forces on real asset prices. Davis and Li [21] include both demographic and nondemographic variables in the econometric specification and use real share price and real bond yields as dependant variables. The empirical estimation consists of two approaches. First, Davis and Li conduct a panel regression analysis for seven OECD countries, termed "panel" and a panel of six countries excluding the U.S. using GLS estimation techniques and fixed effects. Second, they use OLS estimation for the U.S. and for aggregate data for seven countries termed "international" separately. The results suggest a significant relationship between age distributions and real stock prices and real bond yields for all three data combinations of panel, U.S. and international. Also, they report a statistically significant larger positive coefficient of estimate associated with the demographic variable which represents the percentage of population age between 40 - 64 years even in the presence of non-demographic variables. This leads them to conclude that demographic changes, particularly the increase of the population in the age group of 40 - 64 can have a significant impact on stock prices and bond yields.

Geanakoplos et al. [10] identify two variables, namely price-earnings (PE) ratio and rate of return on equity, as the variables that are most compatible with their theoretical model predictions and use data from 1910-2002 for empirical

${ }^{1}$ First 18 developed countries and then 45 developed and emerging economies. 
analysis. They define an MY ratio as the number of 40 - 49 year olds divided by the number of $20-29$ year olds and use it to measure the demographic cycle. According to this measure, they find that the turning points of stock prices and price-earnings ratios synchronize with the demographic cycle. The authors conclude that the demographic variable explains the $14 \%$ of the variability in the rates of return on S\&P 500 during 1945-2002. Contrary to the findings of Poterba [11], they predict a decline in the price-earnings ratio with the predicted behaviour of the MY ratio over the next twenty years.

In addition, Geanakoplos et al. [10] extend the study to examine whether there is a relationship between demographic structure and equity prices for France, Germany, Japan, and the United Kingdom. The mixed findings indicate a significant link between MY ratio and the real price of corporate equities for France and Japan. However, for Germany and the United Kingdom, the relationship is not significant.

Other than stock market returns, Goyal [14] uses net outflow derived as dividends plus repurchases less net issues from stock market. However, Goyal's OLS specification is slightly different from the previous studies' OLS specifications and uses next year net outflows as the dependant variable. The regression analyses give statistically significant positive and negative associations between net outflows from the stock market and the percentage of population over 65 years and percentage of people between $45-64$ years respectively. Thus the results support the traditional life cycle models. Goyal [14] further concludes that average age alone is not an appropriate variable to capture demographic dynamics, which previous studies [16] [19] used.

Goyal [14] considers the case of stock market returns and regresses the excess stock returns on the dividend price ratio and demographic variables in a similar manner to the case of net outflows. He compares the results with the findings of Poterba (2001) and Bakshi and Chen [16]. As with Poterba [11], Goyal [14] is unable to find statistically significant associations with stock returns and demographic variables when the regression models the proportions of populations for different age groups at levels as the demographic variables. However, Goyal [14] finds results supportive of Bakshi and Chen [16] and confirms that stock returns have a positive relationship with average age.

Poterba [20] presents a third study and formulates the econometric specification including demographic variables and some control variables such as the real interest rate and GDP growth and use data from 1926-2003. Further, Poterba [20] conducts the analysis with variables in levels and in first differences and demonstrates that the statistical significance of the results is weaker when the variables are in differences compared to when the variables are in levels. However, Poterba [20] clearly mentions that “... the results of this price level analysis may be subject to 'spurious regression bias' because the dependant and explanatory variables are all slowly trending time series". Thus, conclusions made on level regression may not be sound from the point of view of correct econometric analysis. 
The literature discussed so far investigate empirically single equations that model the link between demographics and stock prices. Jamal and Quayes [22] use a simultaneous equation model incorporating both demand and supply functions to explore the link between demographics and stock prices in the U.S. and the U.K. First, they model the price of stocks with proportion of population between ages 45 - 64 years and then develop a similar model with return on stocks. The estimated results for the United States using annual data from 1950-2000 indicates that a 1 per cent increase in the proportion of the population in 45 - 64 years will lead to an increase of the price-dividend ratio of the $S \&$ P500 by approximately 5 per cent. However, the results do not show a significant association with the return on assets. Further, the U.S. Census Bureau projects a decline in the proportion of the population aged between 40 - 64 years to $28 \%$ in 2030 from $30.4 \%$ in 2000. In this scenario, Jamal and Quayes [22] compute approximately a $39 \%$ drop in the price-dividend ratio in the United States. Similar estimations for the U.K. indicate that stock prices are affected by demographic structure.

Even though Jamal and Quayes [22] find that the variables they use to estimate the reduced form equations are non-stationary, they still use the OLS estimation procedure and make inferences using $t$-tests. Caballero [23] points out that OLS estimates are valid only when the non-stationary regressors and error terms are exogenous and, if not, the subsequent finite sample bias leads to serious problems. In a later study Bae [24] argues that OLS is not valid in such cases for non-stationary data and applies a cointegration approach to estimate the reduced form equation similar to Jamal and Quayes [22]. Bae (2010) employs the dynamic ordinary least square (DOLS) and compares results from the Jamal and Quayes [22] study and makes contrary conclusions. In contrast to the statistically significant relationship between stock prices and proportion of population in prime working age found by Jamal and Quayes [22], Bae [24] finds a statistically significant relationship between stock prices and the proportion of retired population (i.e. those over 65 years).

Ang and Maddaloni [25] use two distinct datasets to examine the impact of demographic changes on future risk premiums. As with Geanakoplos et al. [10], the first dataset comprises the five largest developed countries, (i.e. the G5 countries: France, Germany, Japan, the U.K. and the U.S.) covering a long span of 1900 to $2001^{2}$. Similar to Erb et al. [19], the second dataset includes 15 countries covering a shorter time span (1970-2000) ${ }^{3}$. The empirical analysis uses generalised methods of moments (GMM) estimates and examines predictability of excess returns for three different time horizons.

The results show a weak positive association between demographic variables and excess returns for the U.S. However, the percentage of population over 65 years has a significant impact on excess returns in the U.K. over all three hori-

${ }^{2}$ For Japan (1920-2001).

${ }^{3}$ Australia, Austria, Belgium, Denmark, France, Germany, Italy, Japan, Netherlands, Spain, Sweden, Switzerland, U.K. and U.S. 
zons. At the one year horizon demographic coefficients are significant at 5\% level of significance for Japan, though with the opposite sign to that of the Unites States coefficient estimates. At the same time, results do not show significant relationships between demographics and excess returns for France and German at $5 \%$ level of significance. Based on the pooled and individual country results Ang and Maddaloni [24] conclude that "... demographic changes indeed predict risk premiums internationally".

Brooks [26] addresses the slow moving nature of the demographic changes and uses a long time series over the period 1900-2005 across 16 advanced economies to examine the link between demographic changes and financial asset prices $^{4}$. The empirical specification uses a panel regression and it controls for both country and year fixed effects. Brook's purpose in using a cross section dimension is to implicitly control for non-demographic fundamentals such as global long run business cycles. Further, Brooks [26] constructs demographic variables using a more agnostic approach while criticising the proportion of population in certain age ranges used in literature to define demographic variables. He argues that demographic variables used in previous studies "... arbitrarily partition the age distribution into net savers and net dis-savers ...” [26].

Overall, the Brook's study casts doubt on the previous finding for the relative importance of the middle age cohort's contribution to increases in the real stock and bond prices. Brooks [26] concludes that this relationship does not hold for countries such as Australia, Canada, New Zealand, the U.K. and the U.S., where households' participation in equity market is strong. He demonstrates that increase in old age population affects to raise the real financial asset prices in those economies. In contrast, in countries such as Italy, Finland, Sweden, Norway and Japan where the households' participation in equity markets are limited, the older cohorts and the real stock prices are negatively related. Thus the findings are country specific.

The evidence of the study done by Brunetti and Torricelli [27] also highlights the importance of country specific demographic dynamics in explaining the impact of demographics on financial markets. Italy has experienced rapid population ageing since the 1970s. Brunetti and Torricelli [27] thus identify that Italy has a much steeper pronounced ageing and investigate the empirical connection between population ageing dynamics and financial markets using data from 1958-2004. The statistically insignificant estimates using OLS suggest that demographic variables alone cannot explain the dynamics of the financial asset returns. However, the extended model with a set of explanatory control variables support the theoretical prediction that demographics play a significant role on financial asset returns, particularly stock market returns in Italy.

For the first time in literature Park [28] uses a nonparametric approach to examine the predictions of the life cycle hypothesis empirically for G5 countries. The key feature of his approach is that it relates variations in stock prices to

${ }^{4}$ Australia, Belgium, Canada, Denmark, Finland, France, Germany, Italy, Japan, Netherlands, New Zealand, Norway, Sweden, Switzerland, the U.K. and the U.S. 
variations in the probability density function of the age distribution. This allows the measurement of impacts on asset prices from entire age distribution rather than a particular demographic measure. In contrast to the mixed results found by Brooks [26], Ang and Maddaloni [25] and Geanakoplos et al. [10] for G5 countries, Park [28] concludes a significant impact from prime working age population on the stock prices for all G5 countries. He further computes the age response functions and shows that they are humped shape and significantly positive over prime working ages.

The existing literature on demographics and asset prices fails to accommodate high and low frequency fluctuations in asset prices simultaneously. Researchers concentrate either on low or high frequency fluctuations and ignore the different roles that asset price fluctuations possess at different frequencies. Favero et al. [29] construct the empirical model based on Geanakoplos et al. [10] theoretical model and combine it with dynamic dividend growth as per the derivation of Lettau and Nieuwerburgh [30]. The model formulation captures both high and low frequency fluctuations in a dynamic dividend growth model of asset prices. The results using data from 1910-2008 for the United States provide evidence for high persistence of the dividend-price ratio corresponding to high persistence of middle-aged to young ratio. Thus, it confirms the capability of the demographic trend as measured by the $M Y$ ratio of capturing the slowly evolving mean of dividend-price ratio in the long-run.

\section{Summary of the Survey and Discussion}

The evolution of research concerning the effects of demographic changes resulting from the Baby Boom primarily focuses on the Unites States. The international studies mainly consider developed countries, particularly the G5. Only one study includes emerging economies [19]. The theoretical literature calibrates relevant variables based on inter-temporal general equilibrium or OLG models and then simulates the effects on asset markets of the changes in demographic structure, or provides analytical results. In contrast, empirical literature directly addresses the empirical question of whether there is a relationship between changing demographic structure and asset prices and/or asset returns.

The seminal empirical research papers in the area of demographics and asset prices are those by Mankiw and Weil [15] and Bakshi and Chen [16]. The former examines the relationship between demographics and housing asset prices and the latter concentrates on the link between demographics and financial asset prices, particularly stock and bond returns.

A notable number of empirical papers support the theoretical conclusion that demographic changes should have an impact on asset prices and asset returns. For instance, Yoo [7], Davis and Li [21], Geanakoplos et al. [14], Goyal [14], Jamal and Quayes [22], Ang and Moddaloni [25], Brooks [26], Bae [24], and Park [28] provide plausible arguments that demographic structure, specifically an ageing of population, could have a significant negative impact on financial asset prices. Poterba conducted a series of studies in 1998, 2001 and 2004 that do not 
support a robust relationship between asset prices and demographic structure. Although Poterba's [11], [20] studies find a statistically significant positive associations between stock returns as measured by price-dividend ratio and demographic variables, he concludes that it would not cause a decline in asset prices in the future as suggested by the asset market meltdown hypothesis. Poterba further argues that theoretical models that predict asset market meltdown assume that individuals would sell all their assets at the time of retirement, which is inconsistent with the data.

However, the empirical findings are sensitive to several factors and each empirical specification is open to questions. The first is whether the analysis uses recent data or historical data. The second is which demographic variables and which housing and financial asset variables are included into the model. The third is whether the model is purely demographic or not. And the fourth is whether it is a single country study or a cross country study. The fifth is whether the econometric model is parametric or non-parametric.

The econometric techniques used range from OLS [7] [10] [11] [14] [15] [18] [20] [25], DOLS [24], to panel regression [16] [21] [26], TSCS Regression [19] simultaneous equations [22] [24], cointegrated VAR [29] and non-parametric regression [28]. A notable number of empirical studies use OLS, which ignores the non-stationary properties of time series data, leading to spurious regressions and doubt about the findings. Further, OLS assumes that the association between the selected demographic variable and the asset price variable is linear in nature. In the case of cross country analyses, employing static panel regression ignores any lag effects of the dependant variable. The inclusion of lagged dependant variables as explanatory variables in a dynamic panel could enhance controlling dynamics of the process. These factors may contribute to the mixed results and disjointed interpretations across the studies.

\section{Conclusions}

The objective of this paper is to review the existing empirical and theoretical literature on the effects of population ageing on asset prices, particularly focusing the effects of the Baby Boom generation on financial asset prices. Awareness of the demographic transition and speculation over the possible consequent effects on asset markets prompted the asset meltdown debate. Since the early 1990s there have been numerous papers on the asset meltdown hypothesis, some for some against.

It is clear that the effects of population ageing on asset markets are more complex than predicted by the life cycle theory. The existing literature reveals that the changing age structure has an impact on asset markets, which should not be neglected. An asset meltdown may never eventuate nevertheless it remains plausible that ageing will have a significant negative impact on asset prices. There is also evidence that country-specific age dynamics are important in explaining the relationship between demographics and financial asset prices.

The contradictory views in the asset meltdown debate could be due to the fact 
that during retirement, old people de-accumulate wealth much less rapidly than what the life-cycle theory suggests and there is only modest dis-saving during older ages. Moreover, the traditional approaches measuring the impact of population ageing on asset markets must be rethought. Future research should focus on the dangers of incorrectly invoking the ceteris paribus assumption in linking the increasing size of the old age population due to retiring Baby Boomers to a decline in asset prices. More sophisticated techniques are required to investigate the effects of population ageing dynamics on asset prices.

\section{References}

[1] Modigliani, F. and Brumberg, R. (1954) Utility Analysis and the Consumption Function: An Interpreation of Cross-Section Data. In: Franco, F., Ed., The Collected Papers of Franco Modigliani, Vol. 6, MIT, Cambridge, 3-45.

[2] Ando, A. and Modigliani, F. (1963) The "Life-Cycle" Hypothesis of Saving: Aggregate Implications and Tests. American Economic Review, 53, 55-84.

[3] OECD (2015) Health at a Glance, OECD Indicators.

[4] Siegel, J. (1998) Stocks for the Long Run. 2nd Edition, McGraw Hill, New York.

[5] Diamond, P.A. (1965) National Debt in a Neoclassical Growth Model. American Economic Review, 55, 1126-1150.

[6] OECD (2012) OECD Pension Outlook. http://www.oecd.org/finance/private-pensions/50560110.pdf

[7] Yoo, P.S. (1994) Age Distributions and Returns of Financial Assets. The Federal Reserve Bank of St. Louis, Working Paper No. 94-002A.

[8] Yoo, P.S. (1997) Population Growth and Asset Prices. The Federal Reserve Bank of St. Louis, Working Paper No. 1997-016A.

[9] Brooks, R. (2002) Asset-Market Effects of the Baby Boom and Social Security Reform. American Economic Review, 92, 402-406. https://doi.org/10.1257/000282802320191697

[10] Geanakoplos, G., Maggil, M. and Quinzii, M. (2004) Demography and Long Run Predictability of the Stock Market. Brookings Papers on Economic Activity, 1, 241 325. https://doi.org/10.1353/eca.2004.0010

[11] Poterba, J.M. (2001) Demographic Structure and Asset Returns. Review of Economics and Statistics, 83, 565-584. https://doi.org/10.1162/003465301753237650

[12] Abel, A.B. (2001) Will Bequests Attenuate the Predicted Meltdown in Stock Prices When Baby Boomers Retire? The Review of Economics and Statistics, 83, 589-595. https://doi.org/10.1162/003465301753237678

[13] Abel, A.B. (2003) The Effects of a Baby Boom on Stock Prices and Capital Accumulation in the Presence of Social Security. Econometrica, 71, 551-578. https://doi.org/10.1111/1468-0262.00417

[14] Goyal, A. (2004) Demographics, Stock Markets Flows and Stock Returns. The Journal of Financial and Quantitative Analysis, 39, 115-142. https://doi.org/10.1017/S0022109000003914

[15] Mankiw, G.N. and Weil, D.N. (1989) The Baby Boom, the Baby Bust and the Housing Market. Regional Science and Urban Economics, 19, 235-258.

[16] Bakshi, G.S. and Chen, Z. (1994) Baby Boom, Population Aging and Capital Markets. Journal of Business, 67, 165-202. https://doi.org/10.1086/296629

[17] Bossons, J. (1973) Institutional Investors and Corporate Stock-A Background Stu- 
dy. UMI, 394-428. http://www.nber.org/chapters/c3544

[18] Poterba, J.M. (1998) Population Age Structure and Asset Returns: An Empirical Investigation. NBER Working Paper No. 10851, Cambridge.

[19] Erb, C.B., Harvey, C.R. and Viskanta, T.E. (1997) Demographics and International Investments. Financial Analysts Journal, 53, 14-28. https://doi.org/10.2469/faj.v53.n4.2096

[20] Poterba, J.M. (2004) The Impact of Population Aging on Financial Markets. NBER Working Paper No. 10851, Cambridge.

[21] Davis, E.P. and Li, C. (2003) Demographics and Financial Asset Prices in the Major Industrial Economies. Working Paper, Brunel University, West London.

[22] Jamal, A.M.M. and Quayes, S. (2004) Demographic Structure and Stock Prices. Economics Letters, 84, 211-215.

[23] Caballero, R.J. (1994) Small Sample Bias and Adjustment Costs. The Review of Economics and Statistics, 6, 52-58. https://doi.org/10.2307/2109825

[24] Bae, Y. (2010) Stock Prices and Demographic Structure: A Cointegration Approach. Economics Letters, 107, 341-344.

[25] Ang, A. and Maddaloni, A. (2005) Do Demographic Changes Affect Risk Premiums? Evidence from International Data. Journal of Business, 78, 341-380. https://doi.org/10.1086/426528

[26] Brooks, R. (2006) Demographic Change and Asset Prices. Proceedings of Conference on Demography and Financial Market, Sydney, 23-26 July 2006, 234-258.

[27] Brunetti, M. and Torricelli, C. (2010) Demographics and Asset Returns: Does the Dynamics of Population Aging Matter? Ann Finance, 6, 193-219. https://doi.org/10.1007/s10436-008-0114-6

[28] Park, C. (2010) How Does Changing Age Distribution Impact Stock Prices? A Nonparametric Approach. Journal of Applied Econometrics, 25, 1155-1178. https://doi.org/10.1002/jae.1101

[29] Favero, C.A., Gozluklu, A.E. and Tamoni, A. (2011) Demographic Trends, the Dividend-Price Ratio, and the Predictability of Long-Run Stock Market Returns. Journal of Financial and Quantitative Analysis, 46, 1493-1520. https://doi.org/10.1017/S0022109011000329

[30] Lettau, M. and Nieuwerburgh, S.V. (2008) Reconciling the Return Predictability Evidence. Review of Financial Studies, 21, 1607-1652.

https://doi.org/10.1093/rfs/hhm074 
Submit or recommend next manuscript to SCIRP and we will provide best service for you:

Accepting pre-submission inquiries through Email, Facebook, LinkedIn, Twitter, etc. A wide selection of journals (inclusive of 9 subjects, more than 200 journals)

Providing 24-hour high-quality service

User-friendly online submission system

Fair and swift peer-review system

Efficient typesetting and proofreading procedure

Display of the result of downloads and visits, as well as the number of cited articles Maximum dissemination of your research work

Submit your manuscript at: http://papersubmission.scirp.org/

Or contact tel@scirp.org 